\title{
IMMEDIATE CUSTOM IMPLANT FOR THE MANDIBLE*
}

\author{
E. R. DOOTZ + , R. G. CRAIG $\ddagger$ and F. A. PEYTON $\ddagger$ \\ University of Michigan, School of Dentistry, \\ Ann Arbor. Mich. 48104 , U.S.A.
}

\begin{abstract}
Recent advances in the technology of casting chrome-cobalt alloys for partial denture frameworks has resulted in a technic for fabricating a custom-made mandibular implant during a single surgical appointment. The fabricating procedures are performed during the initial surgery and therefore eliminates the necessity of the patient undergoing a second surgical procedure for attachment of the implant. The implant fits the bone abutments with a high degree of accuracy which offers greater support, rigidity, and immobility to the implant. This method of implant fabrication has practical application for patients suffering from cancer, traumatic injury, or gun shot wounds of the mandible.
\end{abstract}

SINCE the advent of the shell casting technic in dentistry, it is possible to cast chromecobalt alloys in a very short time. The shell casting technic (Dootz et al., 1967, July 1966, and November 1966), provides a means for casting a partial denture framework within one hour from the completion of the wax pattern to the casting of the alloy. The speed at which these alloys may be fabricated suggested the technic could be abbreviated further and used for the casting of alloys for implants in patients suffering from cancer, traumatic injury, gun shot wounds or other accidents of the mandible. It was hoped this new casting technic would provide a means by which the casting, and related laboratory procedures could be accomplished during the first surgical appointment. In this manner a custom-fitted implant could be fabricated for the patient which would fit the mandible abutments more accurately than the standard shaped pre-fabricated surgical implant. The fabricating procedures would be performed during the initial surgery and therefore would eliminate the necessity of the patient undergoing a second surgical procedure for embedding the implant. Also, a custom made implant that fits the bone abutment more precisely would add greater support, rigidity, and immobility to the implant. It was believed that an implant with attachments that fit the abutment with a high degree of accuracy would have a greater chance of success than one that did not fit the abutment and therefore lacked adequate support and rigidity.

\section{CASE REPORT}

The following is a case report in which a mandibular implant was fabricated for a patient suffering from the loss of the left half of his mandible from the symphisis posterior to the angle of the ramus as a result of a gun shot wound\$. A bone graft was performed at the time of the accident, however, the graft was unsuccessful and the decision was then made in favor of a metallic implant.

\section{MATERIALS AND METHODS}

In order to provide a custom-made immediiate implant, yet minimize the fabrication time, simplify the laboratory procedures, and simplify the alignment of the implant within the wound, a method was developed that utilized a three-piece implant, Fig. 1. The main

\footnotetext{
*Received 14 March 1968.

+ Research assistant.

†Professors of dentistry.

Operation was performed at Veterans Administration Hospital, Ann Arbor, Michigan.
} 
body of the implant, or space maintainer, indicated as A in Fig. 1, was fabricated prior to the operation. Five bars were made which differed in length by $2 \mathrm{~mm}$, thus providing the surgeon with a selection. Each bar was designed with a $\frac{3}{16}$ in. hole on each end. The holes will later receive 1 in. balls positioned on the abutment castings, indicated as $B$ in Fig. 1. Additional holes were provided for growth of tissue through the bar. The ball on each abutment casting, and holes in the end of the space maintainer, and the hole in the washer assembly were united by an Allen bolt (Fig. 2). This assembly on each end of the space maintainer provided a double universal joint to aid in the alignment procedure. The balls were welded*, later in the procedure to both ends of the space maintainer and the washer and bolt assembly removed.

Table 1 lists the approximate time required for the various laboratory procedures. The total laboratory time required is about $3 \mathrm{hr}$. However, this does not imply that the patient, surgeon, and staff are helplessly waiting for the laboratory for $3 \mathrm{hr}$. In most instances, there is other surgery required on this type patient which can be performed at this time. There is a need, however, for complete cooperation of the laboratory personnel, and an appreciation for the service being performed by both the surgery staff and the laboratory personnel if this time schedule is to be duplicated. Preplanning is required and consideration given to the smallest detail by all personnel involved if there is to be no costly time delays.

The method was as follows. After the wound was properly exposed an impression was taken of each mandible abutment using dental compound $\dagger$. This was done by softening the impression compound, which is thermoplastic, in water at $133^{\circ} \mathrm{F}$ and then adapting it to the bone abutment using finger
Table 1. Approximate laboratory time schedule*

\begin{tabular}{|c|c|}
\hline & Minutes \\
\hline \multicolumn{2}{|l|}{$\begin{array}{l}\text { Surgical procedure related to preparing } \\
\text { site for implant }\end{array}$} \\
\hline Taking compound impressions & 15 \\
\hline $\begin{array}{l}\text { Pouring and hardening of models } \\
\text { Separation of models from compound }\end{array}$ & 15 \\
\hline impressions & 5 \\
\hline Preparation of wax pattern & 30 \\
\hline \multicolumn{2}{|l|}{$\begin{array}{l}\text { Sprueing, application of aerosol and } \\
\text { water, paint-on-layer of refractory } \\
\text { investment, and application of } 5\end{array}$} \\
\hline shell layers & 15 \\
\hline Burnout at $2000^{\circ} \mathrm{F}$ & 25 \\
\hline Casting of vitallium and cooling period & 5 \\
\hline Finishing of 2 abutment castings & 30 \\
\hline $\begin{array}{l}\text { Sterilizing implant and } \\
\text { surgical alignment procedure }\end{array}$ & - \\
\hline $\begin{array}{l}\text { Welding of ball joint and related } \\
\text { finished procedures }\end{array}$ & 40 \\
\hline $\begin{array}{l}\text { Sterilizing implant and final } \\
\text { surgical fixation of implant }\end{array}$ & - \\
\hline \multirow[t]{2}{*}{$\begin{array}{l}\text { Surgical procedure related to closure of } \\
\text { implant site }\end{array}$} & - \\
\hline & $\begin{array}{l}180 \mathrm{~min} \\
(3 \mathrm{hr})\end{array}$ \\
\hline
\end{tabular}

*Times are not estimated for surgical procedure.

pressure. No impression tray was required as the impression site was small. Care should be taken, however, not to engage any undercuts present on the bone abutments since the impression compound is not elastic. This non-elastic property is of no consequence because the only surfaces of interest on the bone abutment are the buccal, inferior border, the end sectioned surface, and about in. of the lingual surface. The compound impression was washed free of blood and then a model was poured using dental impression plaster $\ddagger$. The impression plaster set in 2-3 min and was removed from the compound impression within $10 \mathrm{~min}$. The plaster models were separated from the compound impression material by again softening the compound in warm water.

\footnotetext{
*Tungsten inert gas welded in argon chamber.

+Kerr Perfection Impression Compound; Kerr Manufacturing Company, 6081-6095 Twelfth Street. Detroit 8. Michigan.

†Impression plaster: Ransom \& Randolph Company, Chestnut \& Superior St.. Toledo. Ohio.
} 


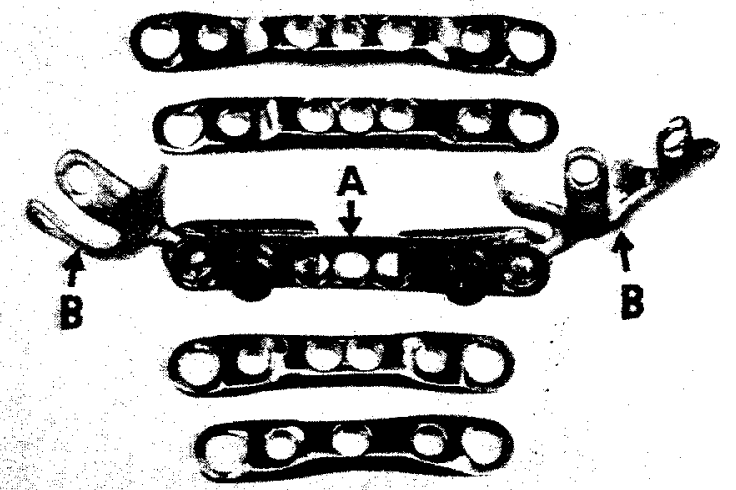

Fig. 1. Three piece implant before welding plus additional space maintainer bars of various length. A-space maintainer.

$B-$ abutment castings.

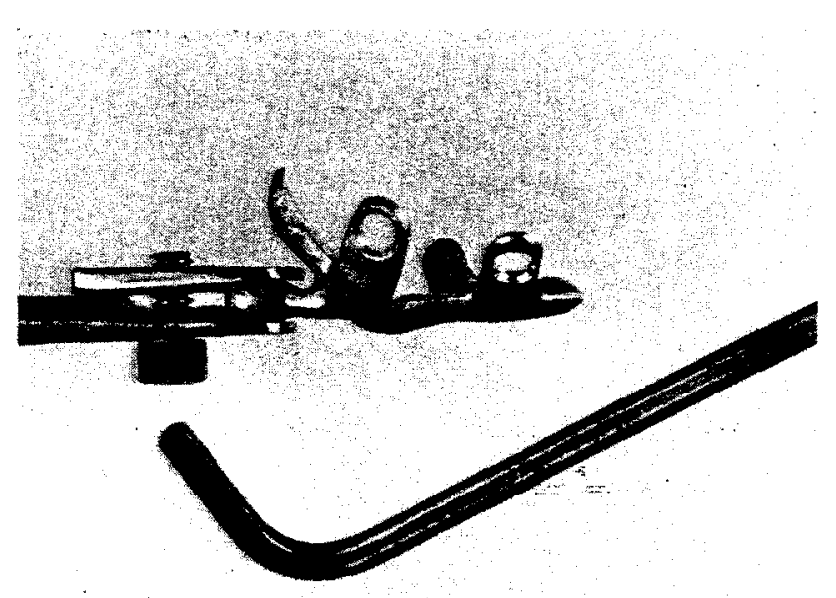

Fig. 2. Close-up of universal joint showing ball abutment casting, washer, Allen bolt and Allen wrench. 


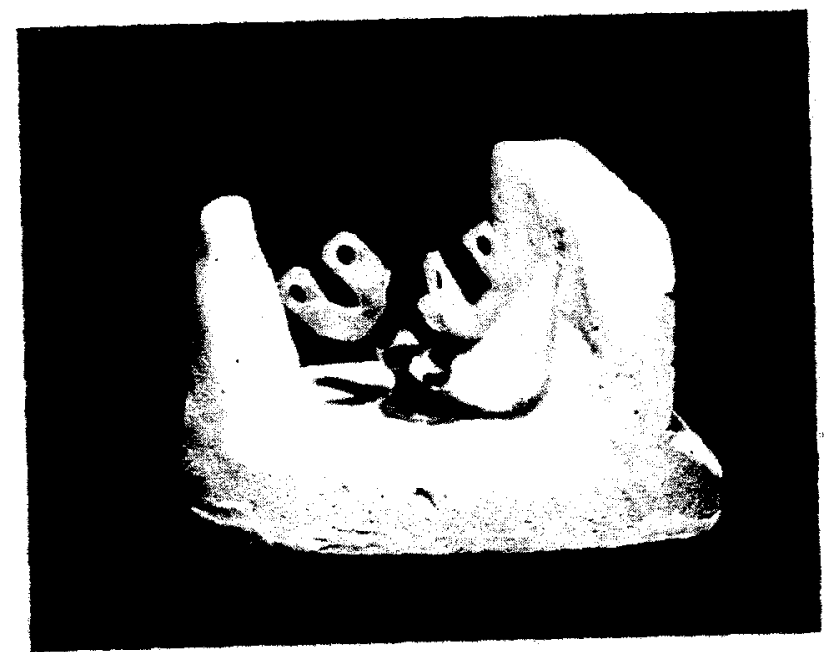

Fig. 3. Wax abutment patterns sprued on phosphate refractory casting base.

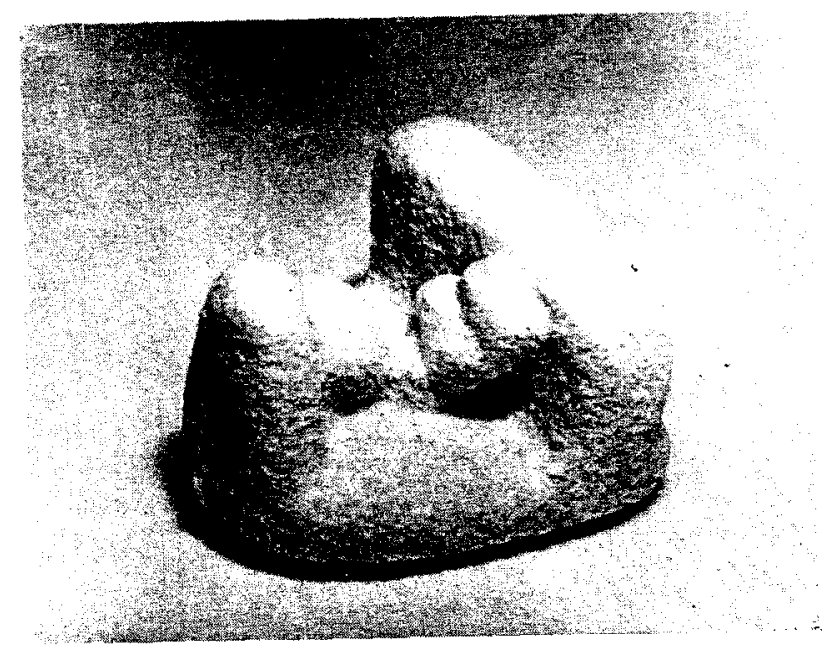

Fig. 4. Five layers of shell casting investment applied to the wax abutment patterns. 


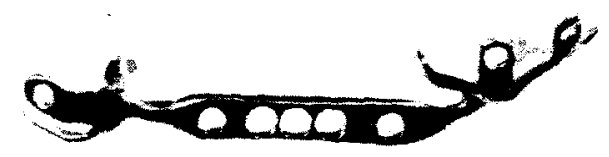

Fig. 5. The implant, welded, finished, and ready for embedding.

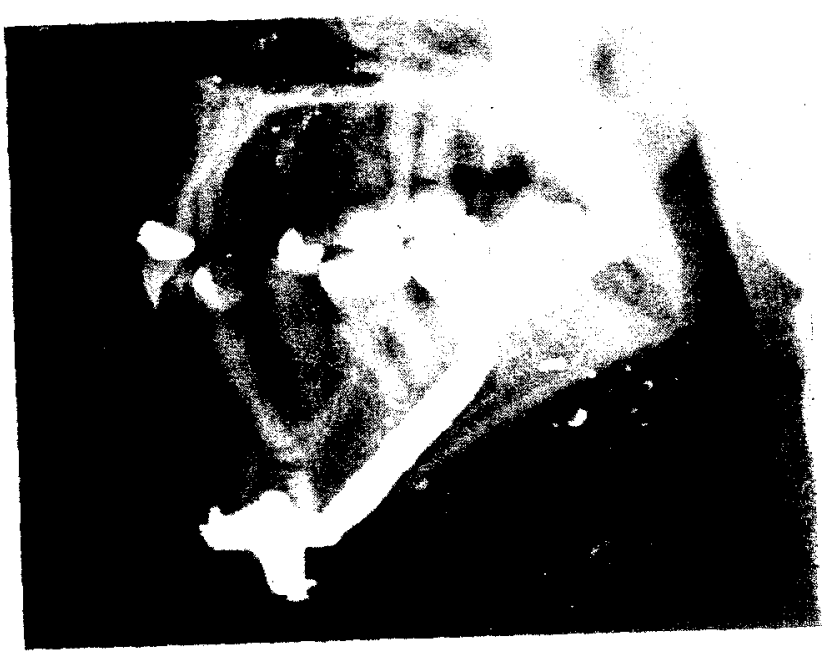

Fig. 6. Radiograph of implant in position. 
Wax patterns were prepared directly on the plaster models in the dental laboratory. Two flat bars, one on the buccal and another on the inferior border of the mandible were waxed in position. In addition, one short flat finger was waxed on the lingual surface to engage the lingual corner of the abutment which prevented the abutment casting from being displaced in a buccal direction. This design provided maximum support for the implant with minimum metal contacting the bone. Holes were drilled and countersunk in the wax pattern to receive the bone screws $\S$. The bone screws used on the buccal bar were long enough to engage both cortices of the bone while the screws for the inferior bar engaged only the inferior cortex. It was believed that having screws positioned $90^{\circ}$ to each other in this manner, provided more support with a minimuin number of screws. A $\frac{1}{4}$ in. Lucite ball (acrylic) was attached by means of a short 10 gauge wax rod, to the approximate center of the wax pattern, and at an angle favorable to the position of the implant.

The wax patterns were carefully removed from the plaster models and sprued to a casting base preformed of phosphate refractory investment* (Fig. 3). The wax patterns were painted with a surface tension reducing agent $\neq$, then a thin layer of the phosphate refractory investment $\dagger$ was painted onto the patterns to eliminate the possibility of trapping air bubbles during the investing procedure. The shell investment material is applied to this investment layer. A detailed description of the shell casting technic has been outlined by the authors (Dootz et al. 1967). Five layers of shell were applied within 3-5 min (Fig. 4). The shell mold was immediately placed into a preheated oven at $2000^{\circ} \mathrm{F}$ for $25 \mathrm{~min}$ and then a casting made using Vitallium Surgical Alloy $\ddagger$. The abutment castings were sand-blasted, electrolytically stripped. and then finished and polished.

The two abutment castings were returned to surgery where they were sterilized and positioned on the bone abutments using only one bone screw on each abutment. The purpose of the single screw was to hold the abutment castings in position while the surgeon selected the proper length space maintainer and made the necessary alignment by virtue of the ball joint assembly. After the alignment was assured and the ball joint locked in position, the entire implant was removed and returned to the laboratory for welding of the ball joint. The welding was done under an argon atmosphere and no welding rod was used. The welding was accomplished by fusing the Vitallium alloy (ball and space maintainer) only in the area of the ball joint. In this manner the three pieces that made up the implant were united as one piece minimizing the chance of electrolytic reaction in the area of the weld which could take place in the presence of dissimilar metals. The area of the weld was finished and polished (Fig. 5) then returned to surgery for sterilization.

Upon the final positioning of the implant all the bone screws were placed and the wound made ready for closure. Figure 6 is a radiograph of the implant in position.

\section{DISCUSSION}

The concept of fabricating a custom-made implant for a patient while the patient is undergoing surgery is quite unique and certainly not possible if the customary castings procedures for chrome-cobalt alloys are employed. The three-piece design of the suggested implant allows for the prefabrication of many space maintainers of various lengths. The prefabrication eliminates the necessity

\footnotetext{
§Vitallium Bone Screws: Austenal Medical Division, 224 East 39th Street. New York 10016.

*Ransom \& Randolph Multi-Vest: Ransom \& Randolph Company. Chestnut \& Superior St.. Toledo. Ohio. +Concentrated solution of Aerosol OT and water: American Cyanamid Co., 1937 West Main Street, Stamford. Connecticut.

$\ddagger$ Austenal Medical Division. 224 East 39th Street, N.Y. 10016, U.S.A.
} 
of casting the space maintainer at the same time as the abutment castings and thereby keeps the laboratory procedures at a minimum. Also, the three-piece design provides the surgeon with space maintainers of various lengths (in this instance differing by $2 \mathrm{~mm}$ ) so a more accurate alignment of the bone abutments can be achieved. After the operation another space maintainer can be cast to replace the one used and the entire series is available for the next operation. At the time of surgery the only castings to be made are the abutment castings.

The self-alignment procedure is quite simple and is done in the wound to assure perfect alignment. The self-alignment feature simplifies the laboratory procedures as no alignment is required which would complicate the technic. The only precautions needed in the laboratory are those pertaining to positioning of the Lucite ball, that is, the ball on the abutment casting must be placed in a position favorable to the position of the implant.

The welding procedure is performed easily without the necessity of employing a welding rod or any additional metal which eliminates the possibility of corrosion from different metals at the site of welding. Also, the surgeon has the freedom to position the space maintainer on the buccal, lingual, inferior, or superior surface of the ball. With this much freedom the surgeon can position the space maintainer in any position favorable to alignment, and it also allows him to release tissue that might otherwise be under tension because of the position of the implant.

It was experienced during the development of this procedure that a great appreciation for the bio-mechanical and bio-material as- pects is required by the laboratory and surgical staff. Not only do the correct materials need to be selected for fabrication of the implant, but the implant itself must be feasible mechanically. The close working relations required between the technical personnel and the surgical staff only exemplifies the need for an understanding of bio-engineering principles by those individuals involved.

\section{SUMMARY}

The shell casting technic was used for casting the abutment castings for a mandibular implant while the patient was undergoing surgery. The speed at which this procedure was accomplished allows for the fabrication and insertion of a custom made Vitallium implant in one surgical appointment. The three-piece design of the implant provides the surgeon with a great deal of freedom to extend, shorten, and align the metallic implant. Also, the design of the abutment casting is such that maximum support is obtained by positioning the bone screws at $90^{\circ}$ to each other with minimum metal contacting the bone.

Acknowledgement-This investigation was supported in part by Contract DA-49-007-MD-938 between the Office of the Surgeon General, Department of the Army and the University of Michigan.

\section{REFERENCES}

Dootz. E. R. Craig. R. G. and Peyton, F. A. (1967) Simplification of the chrome-cobalt partial denture casting procedure. J. prosth. Dent. 17, 464-71.

Dootz, E. R.. Craig, R. G. and Peyton, F. A. (July 1966) A new 'shell casting' technic. Dent. Lab. Rev. 41 14-8.

Dootz, E. R., Craig, R. G. and Peyton, F. A. (November 1966) A rapid-gelling shell casting investment. Precis. Metal Mold. 24, 98-9, 150. 